\title{
LA PROTECCIÓN DEL CONSUMIDOR EN LA COMPRAVENTA DE VIVIENDA: ESPECIAL REFERENCIA A LAS CLÁUSULAS ABUSIVAS
}

\author{
María DíEZ ARNÁIZ \\ GRADUADA EN DERECHO \\ UNIVERSIDAD DE LA RIOJA
}

SumARIO: I. Introducción. II. Marco normativo. II.I. Texto Refundido de la Ley General de Defensa de Consumidores y Usuarios. II.2 Real Decreto 515/I989. II.3. Ley de Ordenación de la Edificación. II.4. Normativa autonómica en La Rioja. III. ¿Quién es el adquirente de vivienda? Breve explicación. IV. Fases previas: las obligaciones legales de información precontractual en la compraventa de vivienda. IV.I. Derecho-Deber de información. IV.2. Obligados. Problemática de la redacción normativa. IV.3. Deber de entrega. IV.3.I. Comportamiento del deudor ¿Activo? IV.3.2. Soporte. IV.3.3. Gratuidad. IV.3.4. Precio. IV.4. Integración de la publicidad y promoción inmobiliarias. V. Precontratos, arras y cantidades anticipadas (cláusulas abusivas). V.I. Precontratos, promesas de compra, reserva de vivienda y cláusulas de cesión. V.I.I. El precontrato y su cesión. V.I.2. Pactos de reserva de vivienda. V.2. Arras. V.3. Cantidades anticipadas. VI. Contenido del contrato. VI.I. Cláusulas establecidas en los textos normativos. VI.I.I. Cláusulas abusivas según el TRLGDCU. A. Gastos derivados de la preparación de titulación. B. Estipulación que obligue a subrogarse en la hipoteca del empresario. C. Que impongan el pago de tributos en los que el sujeto pasivo es el empresario. D. Gastos derivados del establecimiento de los accesos a suministros generales de vivienda. VI.I.2. RD 515/I989. VI.2. Otras cláusulas abusivas en relación con la compraventa de una vivienda. VI.2.I. Cláusula que obliga a concertar una póliza de crédito para el pago de parte del precio e imposición de bienes accesorios o servicios no solicitados. VI.2.2. Cláusulas abusivas por imponer renuncias de derechos del consumidor. VI.2.3. Cláusulas que dejan el cumplimiento del contrato al arbitrio del promotor. VI.2.4. Cláusulas abusivas por falta de reciprocidad. VI.2.5. Otros gastos que no cabe imponer al comprador. VI.3. Efecto de la declaración de abusividad. VII. Protección del adquirente tras la celebración y consumación del contrato (especial mención a la vivienda en construcción). VII.r. Declaración de conformidad como cláusula. VII.2. Superficie. VIII.3. Entrega. VIII. Conclusiones. IX. Bibliografía. XI. Tabla de jurisprudencia.

RESUMEN: En España, la legislación vigente sobre consumidores y la protección de compradores de vivienda supone un compendio difícil de desentrañar. Siendo la compra de la vivienda uno de los mayores hitos en la vida de una persona, resulta complicado para las personas reconocer sus derechos y obligaciones en la misma. Por ello, surgió la necesidad de realizar un estudio legislativo y jurisprudencial, en el que se tratara quién estaba protegido por esta normativa y las cláusulas abusivas que podía encontrar en los contratos de compraventa que vulneraran sus derechos en todo el proceso del contrato: desde las fases previas de información y los precontratos hasta la entrega de la vivienda y su conformidad.

Palabras Clave: consumidores, compraventa de vivienda, cláusulas abusivas, protección de consumidores.

ABSTRACT: In Spain, the current legislation about consumers and the buyers' protection of housing supposes a difficult compendium to unravel it. Being the purchase of the housing one of the greatest milestones in the life of a person, it turns out to be complicated for people to establish his rights and obligations in it. Therefore, arose the need to develop a legislative and jurisprudential study, in which it was consider who was protected by this regulation and the abusive clauses that could be found in the contracts of trade that damaged his rights in the whole process of the contract: from the previous phases of information and the pre-contracts up to the delivery of the housing and his consent.

KEYWORDS: consumers, home purchase, abusive clause, consumer protection. 


\section{Introducción}

España es uno de los países con una tasa de compra de vivienda más alta de la Unión Europea. En el último Censo de Población y Vivienda ${ }^{\mathrm{I}}$, a pesar de su descenso en los últimos diez años, el porcentaje de viviendas en propiedad se encuentra situado en un $78,9 \%$, frente al $13,5 \%$ que lo hacen en concepto de alquiler. Así, la compra de una vivienda supone uno de los momentos más importantes en la vida una persona, sobre todo económicamente, y así lo quiso reconocer nuestra Constitución de i978, que en su art. 47 establece que la vivienda (digna y adecuada) es un derecho al que tienen derecho todos los españoles. Ello, como no puede ser de otra forma, se ha de realizar mediante el establecimiento de una relación contractual.

A todo esto se une un cambio profundo en las circunstancias del país en el panorama de vivienda. Tras la gran crisis que se inició en 2007 con el estallido de la burbuja inmobiliaria (proceso especulativo en el que los precios tanto del suelo como de la vivienda acabada crecían de forma exponencial, revalorizándose), han quedado en España muchas viviendas vacías y terminadas o, bien, en construcción y sin acabar, lo que ha supuesto problemas para las promotoras en relación con los cumplimientos a los que se pudieron obligar antes de la caída de las ventas provocada por la crisis.

En toda relación contractual se presupone que las partes están o deberían estar en posición de igualdad, de modo que todas las cláusulas o estipulaciones se negocien, rechazando la idea de que sean interpuestas por una de ellas. Sin embargo, la realidad contractual es muy distinta: el poder negociador de las empresas, en cuanto se encuentran en una situación más favorable para afrontar la venta que la persona individual con la que contratan, hace que en la actualidad los contratos sean de adhesión, es decir, aquél que sus cláusulas son elaboradas por una de las partes e impuesta a la otra, sin que ésta tenga posibilidad de negociarlas, sino simplemente aceptarlas o no². Es aquí donde se erige la importancia del Derecho de Consumidores, que trata de proteger a las personas que buscan una vivienda (en este caso) de los abusos de los poderes económicos.

Para examinar la especial protección del consumidor en la compraventa de vivienda, se examinará la normativa actual que conforma el marco jurídico de la compraventa de vivienda, con una mención especial a quienes son los protegidos por esta normativa. A continuación, se analizará la protección que se le da al adquirente en las fases de la relación contractual: primero, en las fases previas a la contratación (información, publicidad y figuras como los precontratos); segundo, en las cláusulas establecidas en el contrato que pueden ser declaradas como abusivas; por último, en el momento de cumplimiento de obligación por parte del vendedor, en el que afloran problemas de conformidad o entrega.

Como consideración previa, cabe aclarar que cuando hablemos en este trabajo de los contratos establecidos entre empresa y adquirente se ha de suponer que hablamos de contratos con condiciones generales, o contratos de adhesión, en los que el comprador no

\footnotetext{
' Censo de Población y Vivienda, Instituto Nacional de Estadística, Nota de Prensa I2 de diciembre de 2013.

¿Mondéjar Peña, M.I., «La protección del consumidor en la Compraventa de Vivienda», en Humero Martín, A.E. (Coord.), Tratado técnico-jurídico de la Edificación y del Urbanismo, Aranzadi, España, 2009, Tomo III, pág. IOI8.
} 
ha tenido, realmente, posibilidad de negociar las cláusulas que se le incluyen, y solo ha asumido los derechos y obligaciones previamente redactados por el predisponente (vendedor). Ello es así para no resultar repetitivos en cada apartado, porque las cláusulas abusivas tienen como condicionante que no hayan sido negociadas previamente (lo que se cumple en este tipo de contratos de adhesión o predispuestos).

\section{Marco normativo}

La compraventa de vivienda tiene, en nuestro ordenamiento, una protección específica dentro de la normativa general. Ello, como se ha dicho, se debe a la gran importancia que para el ciudadano español tiene la compraventa de vivienda, y el desembolso que supone, siendo uno de los puntos de más transcendencia en la vida de una persona.

Sin embargo, a pesar del amplio desarrollo normativo, esta legislación se encuentra dispersa en multitud de normas, conformando un laberinto complicado para lograr entender la materia que se trata. Veremos en este apartado los aspectos más generales, desarrollando en los apartados siguientes normativas sectoriales y articulado específico.

\section{II.I. Texto Refundido de la Ley General de Defensa de Consumidores y Usuarios}

Teniendo como punto de partida la legislación de consumidores, la norma básica de protección se encuentra en el Real Decreto Legislativo I/2007, de I6 de noviembre, por el que se aprueba el Texto Refundido de la Ley General para la Defensa de los Consumidores y Usuarios y otras Leyes Complementarias (a partir de ahora, TRLGDCU), en el que encontraremos la normativa que regula deberes de los empresarios y derechos de los consumidores, que al ser aplicables a la compra de cualquier bien o servicio, son aplicables por supuesto a la compraventa de vivienda.

A pesar de esta regulación general, aplicable por ser un bien que entra dentro del ámbito de la ley, nos encontramos artículos en el TRLGDCU que tratan de forma particular determinados aspectos en cuanto el bien se trata de una vivienda, como pueden ser el art. 64, que destaca las obligaciones de entrega de documentación complementaria; el art. I49, que trata el régimen especial de responsabilidad del constructor promotor inmobiliario; o el art. 89.3, en el que se definen específicamente cláusulas abusivas en relación con los contratos de compraventa de vivienda.

No obstante, como es patente en el texto y denuncian algunos autores ${ }^{3}$, la normativa sobre compraventa de viviendas en cuanto la protección del adquirente no ha sido incluida en la norma refundida. La principal razón podría ser la generalización de la protección de otras normas (no solo a consumidores), que quedaría coartada de incluirse en el texto de consumidores, en cuanto protege a los adquirentes, lo que iría contra una tradición de protección extensa al comprador de una vivienda. Y eso ya es patente en la no inclusión en el TRLGDCU de cierta normativa. Otro de los argumentos puede ser la regulación de las

\footnotetext{
${ }^{3}$ MondéJAR PeÑA, M.I., op. cit. pág. 965.
} 
normas bajo títulos competenciales distintos al de consumo (como puede ser el de obligaciones contractuales), lo que complicaría su inclusión en la norma de consumo.

Sin embargo, para tratar el elenco de cláusulas abusivas que pueden formar parte del desarrollo contractual a la hora de comprar una vivienda, el TRLGDCU es el principal punto de partida.

\section{II.2. Real Decreto 515/1989}

Especialmente referido al ámbito de compraventa de vivienda y de rango estatal, se encuentra el Real Decreto 515/1989, de 2i de abril, sobre protección de los consumidores en cuanto a la información a suministrar en la compraventa y arrendamiento de viviendas (RD 515/1989). Aunque dirigida a las primeras fases de la compraventa de vivienda, la información y sus incumplimientos, estos deberes y derechos serán de especial importancia tras la celebración del contrato.

Con todo, es importante remarcar que, según la Disposición Adicional Segunda del mismo, la aplicación de este Real Decreto es supletoria en aquellas comunidades autónomas (CCAA) que hubieran asumido competencias plenas en materia de Derecho de Consumo. En caso de La Rioja es la Ley Orgánica 3/1982, de 9 de junio, de estatuto de Autonomía de La Rioja, en el que se reconoce en su artículo 9.3 que las competencias sobre Defensa de Consumidores y Usuarios se limitan al desarrollo legislativo y ejecución, por lo que el RD 515/1989 es plenamente aplicable en nuestra comunidad. Este desarrollo legislativo se materializó en La Rioja con la Ley 5/20I3, de I2 de abril, para la Defensa de los Consumidores en la Comunidad Autónoma de La Rioja.

\section{II.3. Ley de Ordenación de la Edificación}

Con ella nos referimos a la especial protección que se hace en el ordenamiento de los adquirentes de vivienda, no solo a consumidores. La Ley 38/1999, de 5 de noviembre, de Ordenación de la Edificación (LOE), introduce una serie de garantías que contribuyen a un mayor control de la calidad de las edificaciones, sobre todo tras su reforma de 2015 , por la Ley 20/20I5, de I4 de julio, de ordenación, supervisión y solvencia de las entidades aseguradoras y reaseguradoras. Esta disposición será la que sustituya a la derogada Ley 57/1968, que regulaba la recuperación de cantidades anticipadas por el adquirente de vivienda en construcción.

Además, interesa esta normativa en cuanto regula los documentos que los promotores deben tener a disposición de los adquirentes de vivienda (especialmente el Libro del Edificio), imponiendo esta obligación de nuevo frente a todo comprador, y no solo al consumidor (cuya normativa propia, además, hace remisión expresa en su art. 64 TRLGDCU a la LOE).

\section{II.4. Normativa autonómica en La Rioja}

A nivel autonómico, deben tenerse en cuenta que las distintas CCAA han asumido competencias dispares en cuanto a consumidores. Por no extender el texto, se centrará la 
atención en La Rioja y su normativa. Como se ha mencionado en el apartado anterior (2.2), nuestra Comunidad Autónoma solo asumió en su estatuto de autonomía las competencias de desarrollo y ejecución en materia de consumidores.

El desarrollo lo ha realizado con la Ley 5/2013, de I2 de abril, para la Defensa de los Consumidores en la Comunidad Autónoma de La Rioja (en adelante, Ley 5/2013, de consumidores de La Rioja). Esta norma respeta plenamente las competencias asumidas en el Estatuto de Autonomía y no aporta nuevo contenido en la protección, por lo que tomaremos como base de estudio el TRLGDCU.

También en materia de vivienda, la Rioja cuenta con la Ley 2/2007, de I de marzo, de Vivienda de la Comunidad Autónoma de La Rioja (Ley 2/2007 de Vivienda de La Rioja a partir de ahora), en la que encontramos datos interesantes sobre protección en el desarrollo del contrato, como puede ser la devolución de cantidades indebidas, el carácter vinculante de la publicidad o la Regulación del Libro del Edificio.

Aunque se nombrará en los apartados oportunos la normativa de La Rioja, hay que decir que en su mayoría no plantea novedades respecto a la legislación estatal, por lo que carece de relevancia en cuanto a su explicación más profunda.

\section{III. ¿Quién es el adquirente de vivienda? Breve explicación}

Como ha quedado patente en la explicación del panorama normativo, si bien gran parte de las leyes que regulan la compraventa de vivienda protegen de forma especial al consumidor, otras protegen al adquirente de vivienda (siendo o no consumidor). La utilización en este campo de leyes como la LOE, abre también la protección al adquirente no consumidor. Sin embargo, en este trabajo nos centraremos en la protección al adquirente consumidor.

En este aspecto, hay que recordar que el art. 3 de TRLGDCU define como consumidores a «las personas físicas que actúen con un propósito ajeno a su actividad comercial, empresarial, oficio o profesión». En cuanto a las personas jurídicas, expone en su punto segundo: «las personas jurídicas y entidades sin personalidad jurídica, que actúen sin ánimo de lucro en un ámbito ajeno a una actividad comercial o empresaria». Por tanto, los adquirentes de vivienda a los que nos refiramos serán consumidores, en tanto en cuanto su relación sea con una empresa, puesto que las relaciones de consumidores se han de producir entre éstos y una empresa.

Al margen de tener más o menos clara la condición de consumidor, nos encontramos ya con la primera cláusula que puede crear problemas, precisamente, con la definición de la persona adquirente como consumidora: «La parte compradora podrá escriturar a nombre de las terceras personas, físicas o jurídicas, que estime conveniente». Esta cláusula ha hecho pensar en ciertos casos que el comprador no era un consumidor, en cuanto que evidencia un propósito negocial inmediato, o bien no, si no hay otros indicios que lo corroboren. En La Rioja, nos encontramos con que la jurisprudencia ha considerado (SSAP I23/20I2, de 3 de abril y 27/2013, de 4 de marzo) que perdía su condición de consumidor, generalmente porque no se demostraba que la vivienda fuera para uso privado, ni era el destinatario final. Sin embargo, se ha de comprobar por el tribunal otros indicios 
que indiquen (como en el caso de la SAP 27/2013, en el que el adquirente no vivía, ni pretendía vivir en Logroño) que la finalidad de la vivienda es negocial ${ }^{4}$.

\section{Fases previas: las obligaciones legales de información precontractual en la compraventa de vivienda}

La debilidad de los consumidores es el punto de partida de su especial protección en el ordenamiento jurídico, y es especialmente relevante en el campo de la información. La información asimétrica, es decir, el desequilibrio que se produce cuando una de las partes tiene, por su condición, más información que la otra, está presente en las primeras fases de la compraventa de una vivienda. El consumidor tiene, por lo general, unos conocimientos muy parcos en cuanto a materiales, documentos, y otros elementos relevantes de la compraventa de vivienda, pero está especialmente preocupado por el precio, como no puede ser de otra forma, y de su financiación. Esto puede hacer que la otra parte (ya sea un agente inmobiliario o la constructora) tome ventaja de esa situación, ocultando información o bien confundiéndola, de tal forma que se salven de futuras taras o fallos y de sus reclamaciones.

Ante este panorama, la legislación de consumidores ha desarrollado una normativa compleja en aras de que el adquirente recabe toda la información necesaria y relevante (sin sufrir por ello una sobreinformación), igualando así el desnivel. No hay que olvidar que el derecho a la información no es sólo un derecho básico para el consumidor (art. $8 \mathrm{~d}$. TRLGDCU) sino también un derecho básico de la persona, incluido en nuestra Constitución en el artículo 20.I.d., por lo que se entiende la especial relevancia que tiene dar a los adquirentes toda la información.

En este momento hemos de distinguir varios conceptos que pueden resultar confusos y que pueden acompañar a esta fase, como son la información, la oferta y la publicidad. La oferta (a la que se refiere el art. I262 CC) puede ser entendida como la declaración de voluntad que, aceptada por la contraparte, perfecciona el contrato ${ }^{5}$, y que supone la culminación del proceso contractual. La publicidad puede caracterizarse por la falta de contacto entre partes, y está dirigida a un público general y a captar a aquellos que puedan tener un interés ${ }^{6}$. Más difícil de definir en este momento es información en cuanto importa a los adquirentes de vivienda, pues supone la comunicación o adquisición de conocimientos que permiten ampliar o precisar los que se poseen sobre una materia determinada ${ }^{7}$ Y es que la regulación de ambas es distinta, como se verá, estando el

${ }^{4}$ Díaz Martínez, A., «Cláusulas abusivas en la compraventa de vivienda», en CArrasco Perera, A. (Director), Tratado de la Compraventa. Homenaje al profesor Rodrigo Bercovitz, Aranzadi, Pamplona, 20I3, pág. Io84 (Tomo II)

${ }^{5}$ Alonso PÉREZ, M.T., Las obligaciones legales de información precontractual en la compraventa de vivienda. A través del laberinto normativo, estatal $y$ autonómico en materia de vivienda $y$ de consumo, Aranzadi, Pamplona, 2010, pág. 26.

${ }^{6}$ Definida en la Ley 34/ı988, de iा de noviembre, General de Publicidad, en su artículo 2 como «toda forma de comunicación realizada por una persona física o jurídica, pública o privada en el ejercicio de una actividad comercial, industrial, artesanal o profesional, con el fin de promover de forma directa o indirecta la contratación de bienes muebles o inmuebles, servicios, derechos y obligaciones».

7 Real Academia Española, Diccionario de la Lengua Española, Espasa, Vigésima segunda edición, 200 I. 
empresario obligado a suministrar cierta información, y siendo vinculado en algunos casos por la publicidad dada. Incluir la publicidad en este momento ampliaría la regulación a estudiar (con la Ley de Publicidad y otras) además de la estudiada en el TRLGDCU, por lo que limitaremos el comentario a un somero estudio de la integración de la publicidad.

\section{IV.I. Derecho-Deber de información}

La regulación sobre el derecho de los adquirentes de vivienda se encuentra dispersa en tres normas que exigen un contraste entre ellas, por no ser idénticas en su contenido. Además del TRLGDCU, las obligaciones impuestas al empresario de suministrar información se encuentran en el RD 515/1989 y también en la LOE. Mientras que las dos primeras contienen artículos específicos para la vivienda y sus adquirentes, la LOE establece normativa más genérica, si bien cobra relevancia por la remisión que a ella hace el TRLGDCU.

El TRLGDCU, al margen de establecer un derecho básico de los consumidores, impone en el art. 6o.I al empresario la obligación de suministrar «información relevante, veraz y suficiente sobre las características esenciales del contrato, en particular sobre sus condiciones jurídicas y económicas, y de los bienes o servicios objeto del mismo». Así se configura el derecho-deber de información, como un derecho básico para la parte más débil y un deber para la parte que ostenta el poder en la relación. Será en el art. 6o.2 donde identifique el contenido de dicha información y que ésta, en cuanto es deber del empresario, ha de ser gratuita (art. 60.3 TRLGDCU).

Específicamente, nos encontramos en el TRLGDCU el artículo 64, que impone cierta documentación complementaria a entregar en caso de compraventa de viviendas, refiriéndose a la LOE y su libro del edificio, con remisión expresa a su contenido y también a la normativa que cada Comunidad autónoma se establezca para el deber-derecho de información. Sin embargo, este artículo presenta más dudas que soluciones en cuanto a la obligación ${ }^{8}$ : el término «se facilitará» o cuándo, cómo y por quién se facilitará dicha documentación, dudas que se perfilarán a continuación. Todo ello hace que el artículo 64, lejos de garantizar y afianzar los derechos de los consumidores, suscite más dudas que las que resuelve.

En el RD 515/1989, serán los artículos 4 a 6 los que regulen la información que debe proporcionarse al adquirente de una vivienda. Al margen de la identidad de la persona obligada (que estudiaremos en el apartado 4.3), los restantes se refieren a la identificación gráfica y literaria de la vivienda (art. 4.2 y 3), las calidades empleadas (art. 4.4), instrucciones de uso y mantenimiento (art. 4.5), los datos registrales o expresión de no estar la vivienda inscrita (art. 4.6); en el artículo 5, se refiere al caso de viviendas en promoción, debiendo entregar copia de autorizaciones legalmente exigidas (art. 5.I), estatutos de la comunidad de propietarios (art. 5.2), información tributaria (art. 5.3), forma en que está previsto documentar el contrato (art. 5.4, con menciones especiales a determinadas cláusulas), si se

\footnotetext{
${ }^{8}$ Cámara lapuente, S., «Artículo 64 TR-LGdCU» en CÁmara Lapuente, S. (Director), Comentarios a las Normas de Protección de los Consumidores, Colex, Madrid, 20II, pág. 573.
} 
encuentra o no totalmente construido (art. 5.5) y nombre del arquitecto cuando se trate de la primera compra (art. 5.6).

Por su parte, la LOE solo se refiere a la documentación a entregar en su artículo 7 , donde establece la obligación de entrega del ya mencionado Libro de Edificio, en el que se especifica la documentación que, «al menos», debe entregarse: el proyecto y sus modificaciones, los trámites administrativos realizados, el acta de recepción, la relación identificativa de los agentes que han intervenido en el proceso de identificación y las instrucciones de uso y mantenimiento tanto del edificio como de sus instalaciones.

Como se puede ver con una lectura básica de esta relación de documentos, todos parecen iguales, pero con distinta redacción. Ello produce una confusión evidente, ¿qué elementos se han de entregar? ¿Vale con el Libro de Edificio, que no incluye, por ejemplo, la información tributaria que es preceptiva en el RD 515/1989? Parece evidente que, al incluirse en el art. 64 TRLGDCU la descripción «información complementaria» se han de cumplir los requisitos del artículo $60 \mathrm{y}$, además, por tratarse de vivienda, añadir íntegramente los elementos nombrados en el Libro del Edificio del art. 7 de la LOE, siendo ésta una cuestión pacífica. Sin embargo, queda en duda qué pasa con los requisitos del RD 515/1989 y las otras dos normas. Sobre esta relación se puede argumentar que ley especial prevalece sobre ley general ${ }^{9}$, en cuanto su conflicto con el TRLGDCU: refiriéndose específicamente a la compraventa de vivienda en el caso de consumidores, será el real decreto el aplicable, sin embargo podría decirse que se ha de interpretar en cuanto resulte más favorable al consumidor, entregando la mayor información posible (queda sin embargo de forma muy difusa, la obligación); en cuanto a su relación con la LOE, ésta supone una regulación de mínimos (incluyendo la expresión «al menos»), por lo que se entiende que podrán y se deberán añadir otros documentos ${ }^{\mathrm{ro}}$, en su caso los establecidos en el RD 515/1989 (aunque hay distinción de sujetos, como más adelante se verá).

Hay que resaltar que estas obligaciones de documentación serán especialmente relevantes en caso de compraventa de vivienda sobre plano, ya que la especificación de características, materiales, servicios y espacios será determinante a la hora de establecer la conformidad y probar defectos o faltas de la misma. En la normativa que vemos, solo en algún caso se nombra la posibilidad de que la vivienda no esté aun acabada (en el RD 515/1989), pero toda la información es similar en ambos casos.

\footnotetext{
${ }^{9}$ Como sostiene Torres LANA, que indica que «el RD 5I5/1989 es anterior al texto refundido y enumera, como innovaciones, una serie de contenidos informativos que aparecen también relacionados en dicho texto refundido. Parece que el criterio de especialidad debe prevalecer sobre el rango y la secuencia temporal» (ToRRES LANA, J.A., «Deberes precontractuales de información en las compraventas de inmuebles al consumo» en Carrasco Perera, A. (Director), Tratado de la Compraventa. Homenaje al profesor Rodrigo Bercovitz, Aranzadi, Pamplona, 2013, (Tomo II), pág. IOI3). Sin embargo, Alonso Pérez, indica que el RD 515/1989 debe «ser interpretado a la luz del precepto de rango legal ahora vigente: el reglamento no puede alterar la obligación que se deriva de la ley que desarrolla y ello aunque el alcance de norma con rango legal sea genera y la reglamentaria sea especial y referida sólo a vivienda» (Alonso PÉREZ, M.T., op. cit. pág. 45).

Io Torres LANA, J.A., op. cit. pág. IOI5.
} 
IV.2. Obligados. Problemática de la redacción normativa

Otra de las complicaciones que supone la yuxtaposición de normas en la materia la encontramos en los sujetos a los que protege y obliga el derecho-deber de información. La redacción de las tres leyes plantea problemas en cuanto no utiliza la misma redacción, lo que complica su aplicación simultánea. Como se explicó en el apartado 3, las normas protegen a distintos tipos de adquirentes, y ello es extensible a esta cuestión: mientras que el TRLGDCU y el RD 515/1989 son normas de consumidores, la LOE protege al «adquirente de vivienda». Podríamos generalizar y decir que se encuentra protegido (de una $\mathrm{u}$ otra forma), quien tenga algún interés en la adquisición de una vivienda ${ }^{\mathrm{II}}$.

Sin embargo, la redacción de los obligados plantea problemas:

- En el artículo 6o TRLGDCU, se nombra al «empresario».

- En el artículo $6_{4}$ TRLGDCU, se utiliza la expresión «se facilitará».

- En la LOE, «será entregada».

- El RD 515/1989, se utiliza «Quienes realicen las actividades sujetas a este Real Decreto».

Como se ve, ni siquiera en el TRLGDCU se utiliza la misma expresión, imputándose la obligación en un primer momento al empresario, pero en la normativa específica de vivienda, utilizando una expresión impersonal. En caso de los documentos establecidos en el art. 6o, el empresario con el que el consumidor trata. Más problemático es el art. 64, que remite a la LOE, que utiliza, al igual que ésta, una expresión impersonal: sin embargo, en el primer párrafo del art. 7 de la LOE, se establece que la persona que ha de recibir y, por tanto, tener en posesión dicho libro, indicando expresamente que es el promotor de la obra, pudiendo entenderse por tanto que es éste el obligado a dar el Libro del Edificio.

En el caso del RD 515/I989, se puede considerar que las actividades sujetas al Real Decreto se establecen en el art. I, siendo éstas la «oferta, promoción y publicidad», es decir, a cualquier sujeto que ofrece la venta ${ }^{\mathrm{i}}$. Hay que recordar que, para que la relación sea considerada protegida por el derecho de consumo, la relación se ha de producir entre un empresario y un consumidor, por lo que, necesariamente, las personas que realicen esa oferta de venta han de ser, necesariamente, empresarios ${ }^{13}$.

Será en el artículo 20 de la Ley 2/2007, de I de marzo, de vivienda de la Comunidad Autónoma de La Rioja, la que indique de forma precisa que «Los promotores deberán proporcionar en su oferta de venta a los adquirentes [...] la información básica [...]» ${ }^{\mathrm{I}}$, que aunque deja zanjada la cuestión en un punto, da problemas cuando se incluyen en la transacción intermediarios inmobiliarios.

\footnotetext{
${ }^{\text {II }}$ Alonso PÉREZ, M.T., op. cit. pág. 89. Aunque esto puede ser matizado en caso de la LOE, que nombra a los «usuarios finales de la vivienda».

${ }^{12}$ Alonso PÉrez, M.T., op. cit. pág. 94.

${ }^{13}$ Sillero Crovetto, B., «El Derecho a la información y la protección del consumidor en la compraventa de vivienda», en CAÑIZARes LASo, A., Cláusulas abusivas en la Contratación Inmobiliaria, Tecnos, Madrid, 2006, pág. 35. Esta obra ha sido utilizada con suma cautela, y más como guía y notas sobre argumentos, puesto que es anterior a la reforma del Texto refundido y otras normas ahora vigentes.
}

${ }^{14}$ Alonso PÉrez, M.T. op. cit. pág. iII. 
Así, podría quedar establecido por la LOE y la mayoría de las normas autonómicas (no sólo la de La Rioja se decanta por esta solución ${ }^{\text {I5 }}$ ) que es el promotor a quien el adquirente se ha de dirigir para exigir la documentación.

Sin embargo, toda la anterior regulación, en cuanto no especifica quién es el obligado a entregar la documentación (aunque se puede «adivinar»), deja la puerta abierta (y por tanto, a la aplicación del principio de pro consumatore) a que también sea obligado la persona que entra en contacto con el consumidor y gestiona la venta: puede ser el promotor, pero conviene tener presente que el intermediario también está obligado a informar cuando sustituye en la gestión al promotor ${ }^{\mathrm{r}}$.

Esta obligación será especialmente relevante en cuanto será esencial para establecer la conformidad o no con la vivienda finalmente entregada, que se verá en apartados siguientes.

\section{IV.3. Deber de entrega}

En cuanto a la entrega de todos estos documentos, de nuevo vemos la redacción impersonal y sin concretar que utilizan algunas de las leyes vistas («se facilitará» en el caso del TRLGDCU, «tener a disposición» en el caso de RD 5I5/I989), con lo que parecería que no se impone un comportamiento activo por parte de la empresa con la obligación de informar. Estudiaremos en este apartado si ha de entregarse (en sentido activo), el soporte en el que deber realizarse o si debe ser de forma gratuita o no.

IV.3.I. Comportamiento del deudor ¿Activo?

Según hemos visto en los artículos que regulan el derecho-deber de información, la redacción puede plantear problemas en cuanto utiliza expresiones como «facilitar» o «poner a disposición», que no sugieren la obligación de dárselo al adquirente.

Sin embargo, esta normativa ha de verse complementada por distintos puntos de las leyes mencionadas, en las que sí se indica la obligación de dar, de forma activa, la documentación. Es el caso del RD 515/1989, en su artículo 9 establece el derecho del adquirente de «recibir a costa del vendedor copia de los documentos a que se refieren los artículos anteriores». De la misma forma el art. 60.3 impone que la documentación sea entregada en un soporte duradero (cuando así lo exijan las normas, como es en el caso como hemos visto). Todo ello nos lleva a pensar que, aunque en los específicos artículos se utilicen expresiones vagas, el anclaje en otras normas puede facilitar a los consumidores la exigencia de dicha información.

\section{IV.3.2. Soporte}

La obligación de entrega se reconoce en el artículo 63 del TRLGDCU, en cuanto establece la obligatoriedad de la entrega documentada al consumidor de un «justificante,

\footnotetext{
${ }^{15}$ Cámara Lapuente, S., op. cit. pág. 575

${ }^{16}$ Alonso PÉRez, M.T., op. cit. pág. 90.
} 
copia o documento acreditativo de las condiciones esenciales de la operación», es decir, una confirmación de la contratación realizada.

Esta obligación de entrega, sin embargo, ha de matizarse conforme a la Ley 34/2002, de II de Julio, de Servicios de la Sociedad de la Información y de Comercio electrónico (LSSICE), en cuanto su artículo 23.3 entiende satisfecha esta obligación si se hace de forma electrónica (en todos los dispositivos que, en la actualidad, con el avance de la tecnología, lo permiten) ${ }^{17}$, siendo por tanto suficiente con esa entrega en dichos formatos, por ejemplo, vía e-mail.

\section{IV.3.3. Gratuidad}

El artículo 60.3 del TRLGDCU establece de forma inequívoca que esta documentación, al ser preceptiva por norma, debe entregarse de forma gratuita. Sin embargo, ALONSO PÉREZ señala que la mayoría de las normativas autonómicas no recogen este derecho de forma expresa, lo que complicaría su aplicación ${ }^{18}$. Siendo en nuestro caso una normativa de desarrollo, ha de entenderse que la no mención al coste de la documentación toma por supletoria la norma del TRLGDCU.

\section{IV.3.4. Precio}

Dado el importante desembolso que supone la compra de una vivienda para el bolsillo de un consumidor, resulta normal que la normativa centre su atención en que la información relativa a éste sea lo más precisa posible. El art. 60.2 del TRLGDCU establece que en la información precontractual el precio ha de aparecer de forma completa, incluyendo impuestos o presupuesto en su caso, con desglose de incrementos, descuentos y gastos repercutibles.

No obstante, es el RD 515/1989 el que dedica más artículos a la cuestión. El art. 4.7 impone la obligación del precio total, pero dedicando el artículo 6 al precio de venta. Sin embargo, vuelve a utilizar el impersonal para declarar la obligación de «tener a disposición del público», una nota con los datos relativos al precio: precio total (con honorarios, IVA y otros impuestos); forma de pago (si hay aplazamiento, tipo de interés, y cantidades, con las fechas relevantes); medios de pago admisibles; la previsión de subrogación y las garantías que deberá constituir el comprador.

De nuevo, la problemática con la que nos encontramos es la expresión impersonal y leve de «tener a disposición» que elude la identificación clara (que hay que buscar en el art. I) y el deber de dar la información ${ }^{\text {I9 }}$. Por lo que esta obligación de desglosar el precio en todas sus cantidades, sin poder dejar ninguna al arbitrio futuro se torna más difusa, si bien

\footnotetext{
${ }^{17}$ Según Torres LANA, ello se ve cumplido en los nuevos mass storages (discos duros externos, usb, etc) e, incluso, la colocación de la información en una web site y, seguramente, con más posibilidades de acceso, conocimiento y evaluación (aunque esta última me suscita a mí más dudas, en cuanto no hay control de si se han leído, o puede caerse en la problemática de los «he leído y acepto las condiciones» o medios similares utilizados en la actualidad). TORRES LANA, J.A., op. cit. pág. IOzO.

${ }^{18}$ Aunque termina considerándolo aplicable de forma supletoria, ya que en su mayoría cuando las distintas normas no regulan, se limitan a aplicar el TRLGDCU, es la misma solución que debe aplicarse en este caso. Alonso PÉREZ, M.T., op. cit. pág. I4I.

${ }^{19}$ Torres LanA, J.A., op. cit. pág. IOI8.
} 
al ser uno de los componentes más importantes para el consumidor, suele ser objeto de preguntas claras. Aun así, no resulta completa la protección dada, que es insuficiente y vaga, dando pie a problemas futuros.

IV.4. Integración de la publicidad y promoción inmobiliarias

La publicidad constituye un vehículo de información precontractual al que se impone un deber de veracidad, como confluencia de los distintos intereses: de un lado el interés básico de los anunciantes en promocionar sus productos y servicios; de otro, el interés de los consumidores; por último, el de los competidores, para no verse privados de clientes como consecuencia de una publicidad no permitida ${ }^{20}$.

Las declaraciones publicitarias deben vincular a su autor, aunque no sean ofertas en sentido estricto, de forma que no induzcan a error a los adquirentes de vivienda. Ello queda firmemente reflejado en el art. 6I.2 en cuanto indica «El contenido de la oferta, promoción o publicidad, las prestaciones propias de cada bien o servicio, las condiciones jurídicas o económicas y garantías ofrecidas serán exigibles por los consumidores y usuarios, aún no cuando no figuren expresamente en el contrato celebrado o en el documento o comprobante recibido y deberán tenerse en cuenta en la determinación del principio de conformidad con el contrato».

La jurisprudencia ha estudiado el incumplimiento de las promesas hechas en la publicidad, entre otras las Sentencias del Tribunal Supremo (SSTS) 38I/20II, de 30 de mayo y 518/2013, de 23 de julio, entendiendo que lo prometido en la publicidad (en el primer caso por incluir un edificio donde había campo libre y en el segundo por la falta de un Puerto deportivo) suponía un incumplimiento contractual. De forma más reciente, la SAP Coruña I07/20I5, de 30 de marzo, establece también que la falta de hoyos en un campo de golf (de los I8 previstos, a los 9 reales) y el enlace con la autopista, prometidos en el folleto, son exigibles por el consumidor, aunque su falta no es tan grave como para suponer la resolución del contrato por ese motivo, sino simplemente una reducción en el precio.

La misma disposición se encuentra tanto en la Ley 2/2007 de Vivienda de La Rioja, en su artículo I7 en el que se reconoce el carácter vinculante de la publicidad (apartado 3) y el contenido básico de la misma (apartados 2 y 4).

\section{Precontratos, arras y cantidades anticipadas (cláusulas abusivas)}

V.r. Precontratos, promesas de compra, reserva de vivienda y cláusulas de cesión

Es habitual que, al pretender adquirir una vivienda en construcción, el comprador deba entregar una cantidad de dinero de forma previa o firmar un precontrato. Distintas son las figuras aplicables a este momento de la contratación, donde podemos encontrar los precontratos, las arras, los pactos de reserva de vivienda o las cantidades anticipadas. Sin

\footnotetext{
${ }^{20}$ MondéJAR PeÑA, M.I., op.cit. 978.
} 
embargo, todas estas figuras buscan regular qué pasa cuando una u otra parte desiste antes de llegar a formalizarse el contrato o una vez formalizado este.

\section{V.I.I. El precontrato y su cesión}

El precontrato puede entenderse siguiendo la tesis de ROCA SASTRE ${ }^{2 \mathrm{~T}}$, que indica que surge ya una obligación (siendo ya un contrato) pero que solo obliga a colaborar o cooperar para establecer unas directrices o unos criterios básicos, que las partes deben desarrollar y desenvolver. Puede equipararse según cierta autora ${ }^{22}$ con la promesa de venta. La tesis tradicional define el precontrato como «un contrato cuyo objeto es la celebración de un futuro contrato, o, en otras palabras, el contrato que origina el deber de las partes de prestar posteriormente los consentimientos contractuales apropiados para dar vida al contrato previsto» ${ }^{23}$.

En lo que a este trabajo interesa, es importante reseñar que en el propio precontrato ya pueden aparecer cláusulas abusivas (que se estudiarán en el apartado 6), y que no compete estudiar en este momento. Sí que son atacables en el momento de formalización de la promesa o precontrato, sin esperar a que estén incluidas en el contrato final y, más aún, para evitar que se incluyan ${ }^{24}$.

Sí que interesa establecer si las llamadas cláusulas de cesión del precontrato pueden ser, o no, vedadas por el predisponente. Hablamos de una práctica muy extendida en los momentos del auge inmobiliario, cuando los compradores realizaban un precontrato, cediéndolo al final, con un beneficio debido al incremento especulativo que en aquellos momentos tenían las viviendas. Podría ser que el predisponente prohibiera esa práctica al firmante del precontrato (impidiendo su cesión). Si bien puede considerase que se hace por motivos económicos (para evitar que el comprador especule con la vivienda), no hay equilibrio (a mi parecer) en las posiciones, siempre y cuando en la cláusula solo se le prohíba al comprador ceder su posición ${ }^{25}$.

\section{V.r.2. Pactos de reserva de vivienda}

A través de los contratos de reserva de vivienda, el promotor, a cambio de una señal, reserva al adquirente una vivienda de las que se construirán ${ }^{26}$. No supone así necesariamente la existencia de un precontrato, sino la entrega de cantidades (o bien anticipadas o bien arras, como se verá más adelante), a cambio de una determinada vivienda futura. El problema surge al tratar de determinar qué ocurre con las cantidades entregadas.

\footnotetext{
${ }^{21}$ Definido en Sánchez Hernández, C., «El precontrato inmobiliario», en CAÑIZAREs Laso, A., Cláusulas abusivas en la Contratación Inmobiliaria, Tecnos, Madrid, 2006, pág. 72, que sigue la tesis de RoCA SASTRE.

${ }^{22}$ SÁNCHEZ HeRnÁNDEZ, C. op. cit. pág. 73.

${ }^{23}$ Díez-PiCAzo, L.; Gullón, A.; Sistema de Derecho Civil. El contrato en general. La relación obligatoria; Tecnos, Madrid, II edición, 20I6, Pág. 63.

${ }^{24}$ SÁnChez Hernández, C. op. cit. pág. 777

${ }^{25}$ En contra de lo que establece DiÉGuez Oliva, R., «Las cláusulas de cesión del denominado precontrato inmobiliario» en CAÑIZARes LASo, A., Cláusulas abusivas en la Contratación Inmobiliaria, Tecnos, Madrid, 2006, pág. 8I.

${ }^{26}$ MondéJAR PeÑA, M.I., op.cit. 975.
} 
Aunque se verá en los siguientes párrafos (ver 5.2 arras y 5.3 cantidades anticipadas) qué ocurre con este tipo de cantidades, ya se pueden establecer dos tipos de cláusulas que se prohíben por la legislación de consumidores en este momento:

a) Facultad de resolución unilateral, según las perspectivas que ofrezca en su momento el mercado inmobiliario. No resulta descabellado pensar (sobre todo antes de la crisis) que si, por ejemplo, en 2002 se realiza este pacto, y la vivienda se finaliza en 2005, la vivienda se hubiera revalorizado considerablemente. Esta cláusula está totalmente prohibida $^{27}$ en el art. 85. 3 TRLGDCU y se tendrá por abusiva.

b) Más problemática ha causado la aplicación, tanto a favor del profesional como del usuario, de la cláusula rebús sic stantibus, por la cual se puede modificar o desistir del contrato por determinadas circunstancias sobrevenidas a la celebración. Hay que decir que esta regla ya ha sido examinada por el Tribunal Supremo ${ }^{28}$, en cuanto a sus condiciones: mecanismo excepcional cuando la alteración de las circunstancias sea extraordinaria, es necesario que produzca un desequilibrio exorbitante, y sea consecuencia de circunstancias sobrevenidas y radicalmente imprevisibles (lo que, en principio, dejaría sin opciones a los vendedores, cuando pretendan la resolución por variar el precio al alza). Sin embargo, la llegada de la crisis inmobiliaria puede suponer todo un reto para estas «circunstancias excepcionales e imprevisibles» en cuanto dicha crisis supuso la quiebra de empresas, el corte del crédito, etc. y que también afectó a los compradores, en cuanto tuvieron problemas para conseguir financiación. La jurisprudencia se ha mostrado siempre bastante cautelosa a la hora de aplicar este tipo de reglas, pero la STS IOI3/20I3, de I7 de enero establece claramente: «una recesión económica como la actual, de efectos profundos y prolongados, puede calificarse, si el contrato se hubiera celebrado antes de la manifestación externa de la crisis, como una alteración extraordinaria de las circunstancias, capaz de originar, siempre que concurran en cada caso concreto otros requisitos como aquellos a los que más adelante se hará referencia, una desproporción exorbitante y fuera de todo cálculo entre las correspectivas prestaciones de las partes, elementos que la jurisprudencia considera imprescindibles para la aplicación de dicha regla» (las nombradas anteriormente) ; si bien «no puede fundarse en el solo hecho de la crisis y las consiguientes dificultades de financiación» (en el caso los que pedían la financiación eran los compradores), argumentos que se pueden oponer también a las empresas ( $\mathrm{y}$ en el mismo sentido lo hace la SAP Barcelona 667/2012, de I2 de diciembre). Sin embargo, la reciente y muy completa STS 447/20I7, de I3 de julio, indica que sí hay ciertos casos en que la falta de financiación es una causa que sí permite al comprador liberarse de sus obligaciones: «En los casos en los que el vendedor-promotor asume contractualmente el compromiso de que el comprador obtendrá la financiación [...] mediante la subrogación en el préstamo hipotecario del propio vendedor negocia con tercero [...] la denegación de la subrogación supone un incumplimiento por parte del vendedor y permite al comprador resolver la compraventa»

\footnotetext{
${ }^{27}$ MONDÉJAR PEÑA, M.I., op.cit. 975 .

${ }^{28}$ Busto LAGO, J.M., «¿Cabe aplicar rebús sic stantibus» en un contrato de compraventa como contrato de tracto único?» en Tratado de la Compraventa. Homenaje al profesor Rodrigo Bercovitz, Aranzadi, Pamplona, 20I3, pág. I723 (Tomo II).
} 
siempre y cuando del tenor de la cláusula se entienda que el vendedor está garantizando la subrogación (ejemplos de estas cláusulas en la que el vendedor se compromete son las STSS 805/2012, de I6 de enero, 251/2013, de I2 de abril y 309/2013, de 26 de abril). Sin embargo, si el vendedor no garantiza que la entidad financiera conceda el préstamo (por ejemplo, incluyendo una cláusula como «siempre y cuando el Banco haya consentido expresamente la subrogación»), no es exigible. La reciente STS 447/20I7, de I3 de julio, realiza un resumen de la jurisprudencia completa de la cláusula rebús sic stantibus en un caso de falta de financiación y crisis económica, su efecto respecto a las cantidades anticipadas (que, al no considerarse la crisis motivo de resolución del contrato, son legítimamente reclamadas y cobradas por la parte vendedora).

Así, el cambio en el precio (tanto de forma favorable como desfavorable para las empresas) por motivo de la crisis (como entonces por la burbuja inmobiliaria) no ha de considerarse una circunstancia extraordinaria que permita aplicar esta cláusula. De la misma forma, la imposibilidad de financiación por parte del comprador tampoco permite la exoneración, ya que es un riesgo del deudor (a menos que, como hemos dicho, sea asumido por el vendedor). Así, la inclusión de cláusulas que permitan la resolución unilateral por parte del predisponente debido a la modificación de las circunstancias será abusiva conforme al mencionado art. 85.3 siempre y cuando no disponga lo mismo para el comprador.

\section{V.2. Arras}

Aunque nuestro ordenamiento no regula el contrato de arras como tal, sí contempla en el art. I454 CC las arras penitenciales o de desistimiento. Sin embargo, en el acervo coloquial, sí hablamos de contrato de arras, cuando en realidad es un contrato de compraventa (o de promesa) en el que las partes libremente han incluido un pacto de arras en conformidad con el $\mathrm{I} 454 \mathrm{CC}^{29}$.

El mayor problema con estas arras es determinar cuándo la entrega inicial de una cantidad de dinero del comprador al vendedor se ha hecho en concepto de arras y, en su caso, si éstas son confirmatorias (como señal de la celebración de un contrato, siendo estas arras parte del precio final), si son penales (en cuyo caso se pierden si el contrato no se cumple, pero no permiten la resolución), o bien penitenciales (que sí que permiten resolver el contrato, mediante la pérdida o la devolución del doble de la cantidad, únicas reguladas en nuestro ordenamiento). Según la jurisprudencia, que ha ido desarrollando esta problemática, a menos que de forma inequívoca se establezca otra cosa, se entenderá de forma general que las arras son confirmatorias; a menos que fuera sin especificar nada más, caso en el cual la vaguedad debiera entenderse como las establecidas en el $\mathrm{CC}^{30}$.

En lo tocante a Derecho de consumidores, volvemos a la situación en la que un comprador paga estas arras, dejando el precio aplazado para la consumación del contrato,

\footnotetext{
${ }^{29}$ URrea SAlaZAR, M.J. «El contrato de promesa de compra y las arras en la compraventa de bienes inmuebles», Inmueble: Revista del Sector inmobiliario, $\mathrm{n}^{\circ}$ 156, 2015, pág. 32.

${ }^{30}$ Cabezuelo Arenas, A.L., «Arras confirmatorias y penitenciales: reglas interpretativas» en Tratado de la Compraventa. Homenaje al profesor Rodrigo Bercovitz, Aranzadi, Pamplona, 20I3, pág. I723 (Tomo II).
} 
intentando en ese momento el vendedor dejar sin efecto el contrato y así realizar una venta más interesante desde el punto de vista económico. El TRLGDCU no prohíbe el pacto de arras, pero si le impone limitaciones en cuanto no puede suponer desequilibrio contractual, por el art. 85.3. La jurisprudencia también ha determinado también cierto tipo de cláusulas como abusivas, cuando imponen al adquirente la pérdida de las arras en caso de desistimiento, y en caso de ser el incumplimiento por parte del vendedor, solo la devolución (es decir, suma cero para el vendedor en caso de desistimiento), en las STSS 50I/2008, de 3 de junio (pionera aunque con la aplicación de la normativa de consumidores de I984) y la más reciente 213/20I4, de 2I de abril (Caso Polaris), en el que la consideraban abusiva por suponer un claro desequilibrio en los deberes y penalizaciones de ambas partes.

En cuanto a la jurisprudencia, encontramos el ejemplo de la cláusula a la que nos referimos en la STS 50I/2008, de 3 de junio: «Caso de que el titular de la reservacomprador desistiera de la compra o no se presentase a formalizar y firmar el correspondiente contrato o escritura pública de compraventa dentro del plazo indicado, perderá todo derecho a la reserva, que quedará nula y sin valor ni efecto, y la cantidad entregada en este acto quedará en poder y propiedad de la parte vendedora, conforme a lo dispuesto en el art. I454 CC y en concepto de indemnización por los perjuicios ocasionados y por la limitación de facultad de disposición que esta reserva comporta. Si fuera x quien desistiera de la operación, deberá devolver al comprador la cantidad que hoy recibe como señal o arras». Esta sentencia considera (aunque con fundamento en la ley anterior, ya que el contrato data de i987), que no guardan correlación las obligaciones de las partes y que se produce un desequilibrio importante entre ellas (además de la mala fe de la vendedora, probada en otros aspectos). Una sentencia más actual (STS 213/20I4, de 2I de abril), cuyo contrato data de 2008, incluye la cláusula, pero de forma más intrincada «en concepto de pena civil». La sentencia no considera la cláusula abusiva en cuanto esta cláusula está redactada de forma que se imputen estas cantidades a la indemnización que correspondería por el incumplimiento, y considera el tribunal que no se corresponde la cantidad con las arras establecidas en el art. I454 CC, y por estimar cumplida la prueba de que corresponden con los daños y perjuicios causados a la vendedora. Vemos así que la redacción de la cláusula es importante a la hora de establecer si nos encontramos ante arras o cantidades anticipadas. Aun así, es de señalar que esta última sentencia tiene un voto particular de cuatro de los magistrados del TS, que discrepan y consideran la cláusula abusiva por suponer una falta de reciprocidad en las obligaciones.

\section{V.3. Cantidades anticipadas}

Como la ya derogada Ley 57/1968 ${ }^{31}$ indicaba en su preámbulo, no es extraño que los contratos de compraventa de vivienda se realicen en condiciones especiales, siendo una de las más comunes la de dar como anticipo cierta cantidad de dinero. Surge así la necesidad de establecer con carácter general normas preventivas que garanticen tanto la aplicación real y efectiva de los medios económicos anticipados por los adquirentes y futuros usuarios

\footnotetext{
${ }^{31}$ Ley 57/1968, de 27 de Julio, sobre percibo de cantidades anticipadas en la construcción y venta de vivienda.
} 
a la construcción de su vivienda, como su devolución en el supuesto de que ésta no se lleve a efecto. Sin embargo, esta ley mencionada y que regulaba específicamente la aplicación y devolución de cantidades percibidas está, actualmente, derogada ${ }^{32}$. La sustituyen en su contenido la Ley de Ordenación de la Edificación (LOE), a través de la mencionada modificación sufrida, que incluyó en la Disposición adicional primera, la regulación acerca de la percepción de cantidades a cuenta del precio en la compraventa de vivienda.

La anterior ley 57/I968 establecía el derecho del adquirente de vivienda a reclamar las cantidades anticipadas ante ciertos incumplimientos del promotor (irrenunciable), las vías para tal reclamación y el procedimiento que debía seguir el constructor de la vivienda para garantizar dichas cantidades, de una forma breve y muy práctica ${ }^{33}$.

No resulta sencillo dilucidar si la protección del consumidor ha aumentado o se ha visto disminuida. El nuevo texto recoge la posible constitución de un aval solidario ${ }^{34}$ como garantía en la percepción de cantidades, lo que amplía lo recogido en la LOE y da al garante elección entre ambas (que solo mencionaba al seguro de caución), igualando los mecanismos que aparecían en la Ley 57/196835.

El principal problema de la caución establecida por la Ley 57/1968 lo suscitaba el momento en el que dicha garantía se tenía que realizar. Sí que indica un momento concreto actualmente el nuevo texto modificado de la LOE, indicando que se debe garantizar «desde la obtención de la licencia de edificación» (Disposición adicional primera, tras la redacción dada por la Ley 20/20I5). CASADO CASADO indica que esta redacción no solo no supone una ayuda a la interpretación de cuándo deben garantizarse las cantidades, sino que genera más dudas acerca de qué ocurre con las cantidades dadas hasta ese momento. No puede entenderse, sin embargo, que la persona que entregue las cantidades antes de que la licencia se consiga (venta sobre plano), quede desprotegida, sino que afecta solamente a la constitución de la misma a efectos del banco o aseguradora con el vendedor (es decir, una relación que no afecta al consumidor ${ }^{36}$. De entenderse de otro modo, bastaría con que el empresario exigiera las cantidades antes de obtener la licencia de obra para dejar sin efecto la protección a los consumidores.

En cuanto a qué cantidades quedan garantizadas, de nuevo el texto de 2015 en el que se establece que se debe garantizar la devolución de la totalidad de las cantidades entregadas, más el interés legal e impuestos aplicables, desde la entrega del anticipo hasta la fecha prevista de entrega de la vivienda (Disposición adicional Primera, Uno, 2). En la

\footnotetext{
${ }^{32}$ Derogada por la Disposición derogatoria tercera de la Ley 38/1999, de 5 de noviembre, de Ordenación de la Edificación, que a su vez es introducida por el apartado cuarto de la disposición final tercera de la Ley 20/2015, de i4 de julio, de ordenación, supervisión y solvencia de las entidades aseguradoras y reaseguradoras.

${ }^{33}$ Domínguez Romero, La Recuperación de cantidades anticipadas por el adquirente de vivienda en construcción, Tirant lo Blanch, Valencia, 20II.

${ }^{34}$ Según la STS 739/2016, de 2I de diciembre, también se cumple la realización del aval con una póliza colectiva, sin ser necesario que se realice individualmente

${ }^{35}$ CASAdo CASAdo, B., «Percepción de cantidades a cuenta en la compra de viviendas. Resolución contractual y efectividad de la garantía. Jurisprudencia reciente y reforma tras la ley 20/20I5, de I4 de julio», Revista para el Análisis del Derecho (INDRET) N4, Barcelona, 20ı6, pág. 6.

${ }^{36}$ CASAdo CASAdo, B., op. cit. pág. I6.
} 
regulación de la LOE, se establecen los requisitos que han de tener las garantías y los avales para servir al propósito.

Es importante delimitar los sujetos de este tipo de relaciones, destacando que el obligado a realizar la caución es la promotora, y por tanto el tomador del seguro. El asegurado será el adquirente que pagó esas cantidades anticipadas y que espera, a cambio, una vivienda. Esto es relevante en determinadas situaciones cuando la persona afectada pide directamente la ejecución del aval al banco. Esto ocurre en la STS 218/20I4, de 7 de mayo, en la que el Banco oponía contra el comprador, que reclamaba la cantidad anticipada, que la demora de la entrega no fue tal o que no se probó. Indica la sala que la relación entre avalista y asegurado es automática, es decir, no le corresponde oponer los motivos que sí tendría la constructora frente al comprador, y que ha de pagar el aval si el comprador lo reclama (Fundamento jurídico tercero).

Esto es especialmente relevante en cuanto a las actuaciones de las partes (compradora y vendedora) que puedan perjudicar a la entidad que avala: en STS 547/20I7, de io de octubre, indica que la «inactividad de las partes en la entrega, cuando esta es material y jurídicamente posible», no puede ser motivo para que el comprador reclame a la entidad garante las cantidades anticipadas, ya que en el caso queda probado que las obras se acabaron antes de vencer el plazo y que la licencia de primera ocupación se solicitó dentro del plazo, obteniéndose en la prórroga de 6 meses más que se establecía. El problema radicaba en que la parte vendedora no había comunicado dentro del plazo la fecha de otorgamiento de escritura, pero que tampoco los compradores reclamaron en plazo la entrega de la vivienda, limitándose al tiempo a reclamar las cantidades y pedir la resolución del contrato.

Ante el incumplimiento, hay varias normas que establecen cómo debe actuar la persona y las normas que sancionarán a la entidad en caso de no cumplir con el establecimiento de la caución. En el primero de los casos, la disposición adicional primera, Dos.I. h. (en el caso de contrato de seguro de caución) y Dos. 2. B (en el caso de aval) se establece que si la construcción no llega a buen fin en plazo, y después de que se haya requerido de forma fehaciente al promotor la devolución de las cantidades y éste no las haya devuelto en un plazo de 30 días, la persona puede ir directamente a reclamar al asegurador, que tiene idéntico plazo para devolver la cantidad.

Se recoge, además, que el incumplimiento de estas condiciones establecidas en la legislación supone una infracción en materia de consumo, y se aplican las sanciones que se dispongan en dicha normativa (sanción de hasta un 25\% de las cantidades que deban ser aseguradas, además de otras sanciones, establecido en la Disposición adicional primera, Siete). Sin embargo, en cuanto a la comparativa con la legislación anterior, el aval o contrato sí pierde el carácter ejecutivo que le confería la normativa de la Ley 57/i968, lo cual supone la eliminación de una vía más rápida para el adquirente de la vivienda, que tendrá que realizar más gestiones para su devolución ${ }^{37}$.

Lo más controvertido en cuanto a las cantidades anticipadas supone la opción establecida en el apartado 4 de la disposición adicional primera, que deja elegir entre la

\footnotetext{
${ }^{37}$ CASAdo CASAdo, B., op. cit. pág. 9.
} 
rescisión con la oportuna devolución de cantidades o bien la prórroga, y si este incumplimiento provoca, de forma automática, la opción de resolución. En la STS I60/20I5, de io de septiembre, se llega la conclusión de que la resolución no es procedente cuando no se cumplen ciertos presupuestos (que se pida la resolución antes de que se requiera al comprador para otorgar escritura pública, y que no lo haga el comprador con mala fe, como por ejemplo, no haber opuesto la tardanza en la entrega en todo el período anterior al requerimiento, y sí cuando reclama), pero que la resolución puede darse aunque el incumplimiento no sea especialmente relevante o intenso ${ }^{38}$. En la STS 50I/2015, de I5 de septiembre deja claro que la falta de aval es un incumplimiento esencial (fundamento jurídico cuarto) que faculta al consumidor a resolver el contrato (en el mismo sentido lo hace la STS 65/20I7, de 2 de febrero, en se indica que la falta de aval por parte del vendedor faculta al comprador para dejar de atender los pagos aplazados posteriores al primero, así como la resolución del contrato y la reclamación de las cantidades anticipadas).

También por la jurisprudencia se ha aclarado una práctica que realizaban las aseguradoras y que los bancos utilizaban para no responsabilizarse de las cantidades anticipadas. El caso era el siguiente: en la póliza de seguro sobre estas cantidades anticipadas se establecía una cláusula en la que se aseguraba que «El presente contrato colectivo carece de validez frente a los compradores entre tanto no se emitan las pólizas individuales complementarias» ${ }^{39}$. De no suscribir los compradores dichas pólizas, las cantidades no quedaban aseguradas. Las STSS 739/2016, de 21 de diciembre, 626/2016, de 24 de octubre y la reciente 502/20I7, de I4 de septiembre se pronuncian sobre la vulnerabilidad que generaría para los compradores esta práctica. La STS 502/20I7, de I4 de septiembre, establece que «la omisión del certificado individual a favor de cada uno de los compradores no elimina la responsabilidad de la entidad aseguradora o avalista, conjunta con la del promotor, de garantizar la eventual devolución de las cantidades [...] responsabilidad exigible incluso aunque a los compradores no se les hubiera entregado en su momento una copia de la póliza colectiva» ya que de otro modo recaería sobre el comprador una obligación o diligencia a la que está obligada la empresa vendedora. En ese sentido se pronuncia la STS 626/20I6, de 24 de octubre, en la que indica «No debe pesar sobre el comprador que ha entregado cantidades a cuenta la actuación gravemente negligente o dolosa del promotor que deja de requerir los certificados o avales individuales».

Como apunte, la garantía de devolución de cantidades anticipadas y la aplicación de las mismas cantidades se encuentran reguladas de modo sucinto en la Ley 2/2007, de I de marzo, de Vivienda de la Comunidad Autónoma de La Rioja (arts. 23 y 24), remitiéndose a lo establecido en la Ley 57/1968. Se ha de entender que, así, la referencia actual sería a la LOE, por la derogación por ésta de la Ley 57/1968.

\footnotetext{
$3^{38}$ CASAdo CASAdo, B., op. cit. pág. I2.

${ }^{39}$ STS 3280/20I7, de I4 de septiembre, en el Fundamento de Derecho segundo.
} 


\section{Contenido del contrato}

Una vez superadas las fases de información, negociación y las cantidades dadas como señal, o en otro concepto, el curso normal del devenir contractual marca como perfeccionamiento de la relación la redacción y firma del contrato. Es en este momento sobre todo cuando se establecen los contratos de adhesión o de condiciones generales, que son la norma general en el mundo de los contratos de compraventa inmobiliaria. El vendedor, generalmente empresa (ya sea promotora, constructora, o intermediaria), tiene previamente preparado un contrato con sus condiciones, ante las que el comprador poco más puede hacer que firmarlas, y donde se pueden establecer condiciones verdaderamente injustas.

En este apartado veremos tanto las cláusulas consideradas abusivas como tales por los textos normativos, como aquellas construidas por la doctrina y jurisprudencia. En la actualidad, las más conocidas son las relacionadas con el crédito hipotecario, que no se tratará en este trabajo, pero que siguen las mismas reglas generales.

\section{VI.I. Cláusulas establecidas en los textos normativos}

El TRLGDCU regula en sus Título II Capítulo II las cláusulas abusivas, definiéndolas de forma genérica en el art. 82.I como «todas aquellas estipulaciones no negociadas individualmente y todas aquellas prácticas no consentidas expresamente que, en contra de las exigencias de la buena fe causen, en perjuicio del consumidor y usuario, un desequilibrio importante de los derechos y obligaciones de las partes que se deriven del contrato». Éste será el encaje de cláusulas abusivas que no se encuentren establecidas en la legislación de consumidores. Es importante recordar cómo esta normativa tiene como presupuesto que la cláusula no haya sido negociada individualmente, si un empresario indica que sí lo ha sido, la carga de la prueba recaerá sobre él (art. 82.2 TRLGDCU).

En el articulado del TRLGDCU, encontramos por un lado las cláusulas aplicables a cualquier tipo de contrato (arts. 85-90), encontrando en el art. 89.3 cláusulas específicas referidas a la compraventa de vivienda. Nos centraremos en el estudio de estas últimas, en cuanto no parece efectivo reproducir como copia aquí las cláusulas generales, que si bien pueden ser aplicadas a cualquier contrato, no revisten de especial singularidad. También en el RD 515/1989 encontramos en el art. Io una lista de cláusulas que, en este caso, están específicamente prohibidas para los contratos de compraventa.

\section{VI.I.I. Cláusulas abusivas según el TRLGDCU}

A. Gastos derivados de la preparación de titulación.

Cuando vemos esta cláusula, establecida en el art. 89.3. a. TRLGDCU, podemos pensar en la hipoteca, lo que correspondería más a una cláusula abusiva de tipo bancario que de compraventa inmobiliaria. Sin embargo, podemos pensar el caso también en el que el vendedor impone al comprador gastos de cancelación de las hipotecas concertadas con las entidades constructoras como mecanismo para hacer posible la construcción. Ello es así 
porque el vendedor pretende repercutir en el consumidor gastos que por ley le corresponden a él, siendo el comprador ajeno a la generación de dichos gastos ${ }^{40}$.

B. Estipulación que obligue a subrogarse en la hipoteca del empresario.

Regulada en el art. 89.3.b TRLGDCU, es nula en cuanto obligue al consumidor a subrogarse en el préstamo y la que penaliza la no subrogación. Otra cosa es que el consumidor lo realice de forma voluntaria y libre, pero nunca exigible.

Ligado con esta estipulación, se ha cuestionado desde cuándo han de ser los gastos de estos préstamos asumidos por el comprador. Se descarta que deba ser desde la cédula de habitabilidad, en cuanto atenta contra el justo equilibrio de las contraprestaciones, ya que no hay prestación por parte del vendedor que se ajuste a la obligación que asumiría en ese caso el comprador. Por lo que si hay cláusulas que obligan al pago de los gastos a partir de este momento, serán consideradas abusivas. Así, solo se ha de plantear que los gastos serán asumidos después de la subrogación, siempre que ésta se produzca en un plazo razonable (no vale, por ejemplo, que el comprador se subrogue aún cuando la vivienda no está ni de lejos acabada).

C. Que impongan el pago de tributos en los que el sujeto pasivo es el empresario.

Para las compraventas de vivienda en especial, el art. 89.3. c. establece claramente que el empresario no puede repercutir al comprador el pago de tributos en los que el sujeto pasivo es el propio empresario. Encontramos en este artículo la solución a un problema que no se lograba solventar en la jurisprudencia, respecto al Impuesto sobre el Incremento del Valor de los Terrenos de Naturaleza Urbana (comúnmente denominado Impuesto de plusvalía). Será la STS 25 de noviembre de 20 I la que declare esta cláusula abusiva, por entender (en el caso concreto) que no se dio suficiente información sobre este «sobrecoste» (falta de buena fe) y que supone de nuevo, un desequilibrio contractual en cuanto es el transmitente el que recibe el beneficio del valor añadido (vendiéndolo por más dinero que por el que lo compró), aunque esta sentencia aplica una regulación anterior al TRLGDCU, pero sienta las bases de la argumentación para incluir esta abusividad.

Más problemática suponen impuestos como el Impuesto sobre Bienes Inmuebles (IBI) o el Impuesto sobre Valor Añadido (IVA). En el primero de los casos, dependerá de la fecha de devengo del mismo, lo que determinará si corresponde a una u otra parte ${ }^{4 \mathrm{I}}$. En cuanto al segundo, no parece que entre en el supuesto de hecho del art. 86.3. c. en cuanto no corresponde al empresario el pago del impuesto, sino que es soportado por los consumidores finales.

D. Gastos derivados del establecimiento de los accesos a suministros generales de vivienda.

La protección de este artículo trata de evitar cláusulas que imponían al comprador gastos de alcantarillado, agua, gas, o apertura o cierre de zanjas para ciertos suministros de

\footnotetext{
${ }^{40}$ MondéJAR PeÑA, M.I., op. cit. pág. IO25.

${ }^{41}$ ÁlVAReZ LATA, N., «Cláusulas de repercusión de IVA, plusvalía y otros costes del contrato» en Tratado de la Compraventa. Homenaje al profesor Rodrigo Bercovitz, Aranzadi, Pamplona, 20I3, pág. 996 (Tomo II).
} 
la vivienda. El art. 85.3. c establece esta obligación cuando el vendedor deba entregar la vivienda en condiciones de habitabilidad.

VI.I.2. Cláusulas prohibidas según el RD 515/1989

Se establece la prohibición de inclusión de ciertas cláusulas en el artículo io del RD 5I5/1989 que declara la ilicitud de las cláusulas por ser contrarias a normas imperativas. Encontramos así:

- Las que no reflejen con claridad $u$ omitan todos aquellos supuestos en que se faculte al vendedor a incrementar el precio aplazado.

- Impongan un incremento del precio por servicios, financiación, aplazamientos, etc. que sean accesorios y no puedan ser rechazados libremente por el comprador. Se establecen algunos casos en los que ciertas reformas (apartados I y 2), deben ser documentadas y previamente aceptadas.

- Supongan la repercusión al comprador de fallos, defectos o errores administrativos o bancarios que no les sean imputables.

- De nuevo nombra la imposición de gastos de preparación de titulación.

Si bien parece que la normativa no completa en nada a lo establecido en el TRLGDCU, hay que tener en cuenta que este real decreto es anterior al actual texto refundido, y que sí supuso concreciones para los contratos inmobiliarios en relación con las cláusulas abusivas.

VI.2. Otras cláusulas abusivas en relación con la compraventa de una vivienda

Al margen de las vistas específicamente para la compraventa de vivienda en la normativa, nos encontramos con otras cláusulas que son, de modo habitual, insertadas en esta materia que han sido declaradas abusivas o bien por la jurisprudencia o bien por encajar en otros supuestos de cláusulas abusivas del texto refundido. Dejaremos para más adelante algunas que por su especial relevancia en la ejecución del contrato (como es la conformidad, el plazo de entrega) pueden verse de forma autónoma.

VI.2.I. Cláusula que obliga a concertar una póliza de crédito para el pago de parte del precio e imposición de bienes accesorios o servicios no solicitados.

Esta cláusula de por sí parece compleja, puesto que no dice con claridad qué parte del precio ni para qué sirve esa póliza que se obliga a contratar. La SAP Madrid 462/2007, de I8 de septiembre, entendió que lo que se pretendía con esta cláusula era un subterfugio ideado para que la compradora asumiera los intereses del préstamo hipotecario otorgado al promotor para financiar la construcción ${ }^{42}$ (de forma bastante liosa), por lo que se puede entender no solo que esta cláusula debe ser entendida como abusiva por suponer un fuerte desequilibrio entre las partes (como establece la Sentencia en su fundamento jurídico cuarto) sino también por no ser clara ni precisa en su pretensión, en tanto la expresión «póliza de crédito para el pago de parte del precio», puede no ser entendida a qué parte del

${ }^{42}$ MondÉJAR PeÑA, M.I., op. cit. pág. IO28. 
precio se hace referencia, y por tanto declarar su abusividad por el art. 89.5, ya que supondría un incremento del precio por un servicio accesorio, que encima oculta el pago de unos intereses que son obligación del empresario.

Estos bienes accesorios o servicios no solicitados no cuentan, cuando se incluyen en el contrato, con un verdadero consentimiento por parte del consumidor, en cuanto no ha negociado la inclusión de estos bienes o servicios y suponen el aumento del precio. En ese camino va el art. IO.B del RD 515/1989, que incluye también ciertas reformas y establece como necesario recabar de nuevo el consentimiento del consumidor.

VI.2.2. Cláusulas abusivas por imponer renuncias de derechos del consumidor

En esta categoría de cláusulas abusivas encontramos, entre otras, las cláusulas de renuncia a la elección de notario (art. 89 TRLGDCU), de sumisión a determinados tribunales o arbitraje (art. 90 TRLGDCU) o de renuncia de las garantías exigidas a los promotores en leyes (como puede ser la LOE) (3) $^{43}$

VI.2.3. Cláusulas que dejan el cumplimiento del contrato al arbitrio del promotor.

Como ya vimos en el apartado (vid. V.2), las cláusulas de arras son entendidas abusivas por entender que esa penalización solo del consumidor implica que el promotor tiene libertad absoluta a la hora de desistir o no. Así, cualquier cláusula que, bien sea por penalizaciones, o cambios de circunstancias (ver cláusula rebus sic stantibus en vid. V.I.2) permita modificar ciertas condiciones unilateralmente o bien desistir supondrán ser cláusulas penadas por el art. 85.3 TRLGDCU.

\section{VI.2.4. Cláusulas abusivas por falta de reciprocidad}

Podemos encontrar en algunos contratos de compraventa de vivienda que se establece que se penaliza al comprador por el retraso del pago del precio y no se pone igual pena al empresario en caso de retraso en la entrega de la vivienda; o bien que el comprador está obligado a pagar el precio aun cuando no se haya entregado el inmueble. En todos esos casos, la falta de reciprocidad de las obligaciones se ve sancionada en el art. 87 TRLGDCU, que provoca grandes desequilibrios en las posiciones contractuales.

\section{VII.2.5. Otros gastos que no cabe imponer al comprador}

En la construcción de viviendas se ha pretendido derivar al comprador obligaciones de pago que son, por su dedicación a ello, obligación del empresario. Nos referimos al pago de la licencia de primera ocupación, gastos de comunidad de propietarios anteriores a la transmisión, primas de seguro sobre los inmuebles anteriores a la transmisión de la vivienda, o costes administrativos de ciertas inspecciones preceptivas. Todos ellos son gastos que son anteriores a la transacción del inmueble, y que por ello han de ser pagados por la promotora, en aras de ser necesarios además para la habitabilidad de los inmuebles (art. Io.D. RD 515/1989).

\footnotetext{
${ }^{43}$ MondéJAR PeÑA, M.I., op. cit. pág. IO29.
} 
VI.3. Efecto de la declaración de abusividad

El efecto de la declaración de abusividad se encuentra regulado en el art. 83.I TRLGDCU, en el que se establece que la sanción es la nulidad y, por tanto, se tienen por no puestas. Hay que recordar que, hasta 20I4, el juez podía moderar los importes o bien integrar el contrato según su entendimiento del concepto de justicia (cosa que declaró contraria a derecho el TJUE en sentencia de 30 de mayo de 20I3, lo que provocó el cambio legislativo español por ley 3/20I4).

\section{Protección del adquirente tras la celebración y consumación del contrato (especial mención a la vivienda en construcción)}

En las compraventas sobre plano o en construcción aún temprana, es esencial para el consumidor que se cumplan debidamente los deberes de información, que le permitan saber de forma precisa el objeto que le será entregado a cambio del precio ya estipulado. Particularmente esta obligación ha tenido problemas a la hora de entrega en dos puntos esenciales: la superficie y la fecha.

Desde el punto de vista de las viviendas sobre plano, los deberes específicos de información se encuentran regulados en el RD 515/1989, en el art. 4.3 (que obliga a la información de la vivienda con descripción de superficie útil, y del edificio, zonas comunes y servicios accesorios), art. 7 (de documentación de las garantías dadas por los compradores) y el art. 5.5. (en el que se obliga a incluir en la información la fecha de entrega y la fase en que en cada momento se encuentra la edificación). Con estas obligaciones presentes, veremos qué problemas surgen tras la entrega de la vivienda y qué tipo de cláusulas limitan los derechos de los consumidores en este momento.

\section{VII.I. Declaración de conformidad como cláusula}

Llama poderosamente la atención en algunos contratos de compraventa, cuando se produce sobre plano o en construcción, la inclusión de una cláusula similar a la siguiente: «El comprador declara conocer y aceptar el estado físico y jurídico de la finca, renunciando por ello a reclamar de la propietaria la posible diferencia existente con respecto a los planos o defecto de cabida, así como la exigencia del saneamiento por vicios ocultos». Nos encontramos así, con una declaración de conformidad en un contrato de adhesión, que tiene cierta problemática: en una casa ya construida, el comprador ha podido visitarla, realizar las comprobaciones oportunas antes de aceptar el contrato de compraventa; sin embargo, ante una venta sobre plano o aún en construcción, parece imposible que el comprador haya podido efectuar las efectivas comprobaciones sobre el terreno, sino simplemente fiarse de lo que la información previa le suministró sea cierto en un futuro.

Encontramos en TRLGDCU el artículo 89.I, en el que se establece como abusivas: «Las declaraciones de recepción o conformidad sobre hechos ficticios, y las declaraciones de adhesión del consumidor y usuario a cláusulas de la cuales no ha tenido oportunidad de tomar conocimiento real antes de la celebración del contrato». Así, cuando sea patente que 
el consumidor no pudo, en ningún caso, «conocer y aceptar el estado físico y jurídico», en cuanto supone un reconocimiento real de la futura vivienda, entiendo que se trata de una conformidad sobre hechos ficticios que resultaría nula: si el comprador no tuvo posibilidad de confrontar lo pactado con la prestación (por no haber examinado la vivienda) o bien siendo el examen insuficiente, en cuanto los defectos solo podrían advertirse al habitar la vivienda ${ }^{44}$.

Además, esta cláusula puede incluirse en el tenor de art. 86.I y 2 TRLGDCU, en cuanto supone la renuncia a la reclamación por diferencias o vicios ocultos y la limitación de la responsabilidad del constructor, sancionadas por la legislación de consumidores. La STS I5I/20II de I6 de marzo entiende que dicha cláusula de ningún modo puede anular la normativa de protección sobre vicios ocultos o reclamaciones posteriores.

Se establece también en la jurisprudencia que, en cuanto haya discrepancias en la conformidad, el contrato ha de interpretarse (por ser cláusulas en contratos de adhesión, redactadas solo por la parte vendedora) en contra de quien las estableció (art. I288CC). En la STS 983/2000, de 24 de octubre, se señala esta regla para el caso en el que se instala una calefacción individual, cuando lo contratado era calefacción central, siendo de relevancia también que no se pusiera en conocimiento de los demandantes el cambio de tipo de calefacción.

\section{VII.2. Superficie}

En las ventas sobre plano de viviendas, éstas no son una realidad, sino que constituyen un «objeto futuro», aunque gráficamente el adquirente pueda tener una idea de qué es lo que resultará de ellas. En este tipo de contratos el consentimiento se otorga basándose en las características resultantes del plano dado o bien de la publicidad recibida ${ }^{45}$. Hay que decir que la superficie puede considerarse, en la actualidad, un dato esencial en el marco de la contratación inmobiliaria ya que, en general, el precio de las viviendas tiene mucho que ver con el precio del $\mathrm{m}^{2}$ de suelo, dada su carestía actual (y más antes de la época de crisis inmobiliaria).

Por ello, es esencial que el resultado final se ajuste a lo que la promotora prometió en la información (recordando que uno de los deberes de información es la superficie útil de la vivienda, regulada en el art. 4.3. del RD 515/1989, cuando se encuentre en construcción). En el caso que esta obligación se omita, la STS 277/2002, de 20 de marzo estableció que, si surgen dudas, al ser una cláusula predispuesta, habrá de interpretarse en contra de quien redactó el contrato. En este caso, se establece en el contrato que el piso tiene una superficie de $1 \mathrm{6} 6,8 \mathrm{~m}^{2}$, siendo la superficie útil final de $96,60 \mathrm{~m}^{2}$. El tribunal considera que la mera referencia a la superficie, sin precisar a qué tipo se refiere (si construida o útil) debe entenderse en favor del consumidor, y por tanto, como útiles,

\footnotetext{
${ }^{44}$ DíAz MARTínEZ, A., op. cit. 1084.

${ }^{45}$ MondéJAR PeÑA, M.I., op. cit. pág. I036.
} 
existiendo una diferencia entre los metros cuadrados prometidos y los reales de casi 20 metros, por lo que será motivo para la resolución del contrato ${ }^{46}$.

Es problemática la venta de ciertas fincas o casas en lo que se denomina «precio alzado», indicando la STS 6r/ı999, de 2 de febrero, en el mismo sentido que «si se señala por sus linderos [...] y se designa su cabida o medida, el vendedor tiene que entregar lo que se halla dentro de los linderos, aunque exceda de la cabida o medida señaladas, pero si no puede hacerlo, sufre la rebaja del precio o la resolución» haciendo entender que al establecer cierta medida, han de atenerse a ella y que la falta de dichos metros puede suponer una rebaja en el precio o bien la resolución.

VII.3. Entrega

Con independencia del resto de obligaciones del vendedor, la finalidad última del contrato de compraventa es la entrega efectiva de la misma al comprador. La entrega en este caso cobra especial relevancia cuando se trata de compraventa sobre plano de viviendas en construcción. El mayor problema se plantea con la fijación en el contrato de los plazos de entrega y, en especial, su incumplimiento. De nuevo la época de crisis que hemos vivido, ha hecho que muchas viviendas quedaran sin acabar, o retrasaran de forma evidente el cumplimiento de su obligación. Todo ello requiere una especial protección para el consumidor que, unido a la protección de la devolución de cantidades indebidas vistas, hará que la compra sobre plano sea segura y deseada.

Es importante resaltar que según la Sala del Tribunal Supremo en la reciente STS $547 / 2017$, de Io de octubre, la fecha en la que la parte vendedora puede proceder a la entrega de la vivienda debe entenderse en cuanto «ésta esté terminada y en disposición de ser entregada dentro del plazo establecido en el contrato», es decir, no tanto fijándose en la entrega material o instrumental (entrega de llaves $u$ otorgamiento de escritura). Indica así que la «inactividad de las partes en la entrega, cuando esta es material y jurídicamente posible», no puede ser motivo para que el comprador reclame a la entidad garante las cantidades anticipadas.

Se pueden resumir las irregularidades que se pueden presentar en relación al plazo de entrega de la vivienda en las siguientes: falta de especificación en el contrato o fechas aproximativas que no vinculan; plazo sometido a la condición suspensiva (para, por ejemplo, obtención de licencias); previsión de prórrogas automáticas; y por último, causas de fuerza mayor o no imputables a la promotoras.

En cuanto a las dos primeras irregularidades, el RD 515/1989, establece claramente en su art. 5.5 la obligación del constructor, en cuanto se trate de viviendas no completadas, de informar «con toda claridad» de la fecha de entrega. Lo mismo realiza el art. 85.8, que declara abusivas las cláusulas que establezcan fechas meramente identificativas. Así, estos artículos permiten la declaración de abusividad de una cláusula en la que o bien no se

\footnotetext{
${ }^{46}$ MondéfAr PeÑa, indica que esto se debe a una doctrina de TS, en cuanto supone el incumplimiento de la obligación por haber sido entregado una cosa distinta de la pactada según ciertos criterios (cosa objetivamente distinta, el objeto resulte totalmente inhábil, o bien la insatisfacción del comprador sea objetiva) op. cit. pág. I043.
} 
establezca de forma clara o sea imprecisa la fecha de entrega, ya que vincularía el cumplimiento del contrato únicamente a la voluntad del empresario ${ }^{47}$. Así se puede encontrar esta protección también en el TRLGDCU, en cuanto el art. 85.I sanciona como abusiva la cláusula que establezca un plazo excesivamente largo para la satisfacción de la prestación debida.

En lo que se refiere a las prórrogas automáticas, el mismo fundamento permite establecer esa cláusula como abusiva: vincula el cumplimiento del contrato a la voluntad del empresario. Se encuentra específicamente sancionado en el art. 85.2. Impone como condición para éstas que el consumidor no tenga, efectivamente, forma de indicar que no quiere prorrogarlo. Resulta frecuente, en el ámbito de la construcción, dichas prórrogas, que se entenderán abusivas solo cuando sean excesivamente amplias, siempre y cuando se haya dejado clara la fecha de entrega a partir de la cual estas prórrogas entran en funcionamiento $^{48}$. Por tomar un ejemplo, la STS I88/2013, de 21 de marzo considera procedente la resolución del contrato en el que el plazo de entrega se fijaba en treinta meses desde la concesión de la licencia de edificación, habiéndose demorado el vendedor incluso por encima de ese tiempo extra.

Sobre a las cláusulas que establezcan condiciones suspensivas, o bien limiten el cumplimiento en caso de fuerza mayor o causa no imputable al empresario, de nuevo nos encontramos ante disposiciones que buscan vincular a la mera voluntad del empresario el cumplimiento del contrato y, en el segundo caso, que limitan la responsabilidad del empresario. Todo ello se encuentra sancionado en el art. 85.3 del TRLGDCU, en cuanto el empresario no puede dejar a su arbitrio el cumplimiento del contrato. En este artículo se establece que puede ser si concurren motivos válidos especificados en el contrato (aparición de tubo volcánico, aparición de agua dulce, lluvias torrenciales $)^{49}$. Como se ha establecido antes, surgen problemas si la crisis financiera sufrida estos años atrás puede considerarse motivo suficiente para considerarse una causa de fuerza mayor o no. Así la jurisprudencia se ha definido sobre el particular en la STS 744/2014, de 22 de diciembre, indicando, en su fundamento jurídico tercero: «el hecho que ha determinado un retraso tan notable en el cumplimiento de su obligación por parte del recurrente no puede atribuirse sin más y en general a la crisis inmobiliaria y financiera, pues ello determinaría que el retraso se extendiera de igual forma a todas las promociones, sino que ha de concretarse en circunstancias individuales como resulta ser en este caso (...) una falta de financiación particular que dio lugar a que no se pudiera hacer frente al pago por la promotora de la suma de 2.000.000 euros que le exigía el convenio alcanzado con el Ayuntamiento, que supuso la paralización de la obra por parte del último; situación que a la vista de los compromisos adquiridos no resultaba totalmente imprevisible para dicha promotora y que se desenvolvía en el ámbito propio del negocio emprendido». Ello indica que este motivo no puede ser considerado de fuerza mayor de forma general, sino que ha de concretarse en los motivos individuales que llevan a que no se pueda realizar la entrega, siempre que no haya

\footnotetext{
${ }^{47}$ LUQUe JimÉnEZ, M. C., «La cláusula reguladora del plazo de entrega de la vivienda» en CAÑIZARES LASo, A., Cláusulas abusivas en la Contratación Inmobiliaria, Tecnos, Madrid, 2006, pág. I49.

${ }^{48}$ Díaz MarTínez, A., op. cit. 1085.

${ }^{49}$ LUQUE JIMÉNEZ, M.C., op. cit. I6O.
} 
sido previsible. En el mismo sentido lo hace la STS 5II/20I3, de I8 de julio, en cuanto indica que la paralización de la obra imputable a la conducta antijurídica de la promotora (presentación de un proyecto ilegal), no excusa el incumplimiento, puesto que es imputable a la empresa.

Y por último, en el estudio de la jurisprudencia, cabe resaltar la STS 476/20I5, de Io de septiembre, en la que indica que el retraso meramente no faculta solamente a una resolución de forma automática, sino que tiene que completar ciertas condiciones: que el comprador no tenga mala fe (en el caso se acredita ya que, en los 6 meses que pasa de retraso, no inquiere en ningún momento a la vendedora, para hacerlo tras la reclamación de resolución) y una actuación que si bien puede ser con un retraso o incumplimiento que puede no ser especialmente intenso o relevante, ha de realizarse antes de ser requerido por el vendedor por el otorgamiento de escritura pública (Fundamento jurídico 4). También lo hace la STS 56r/20I6, de 23 de septiembre, en la que indica que, a pesar de la no estipulación en el contrato de la fecha, ello no es motivo para que los compradores resuelvan por ese motivo el contrato, cuando la empresa puso en disposición la vivienda en un plazo razonable y los compradores no reclamaron el establecimiento de fecha de entrega (y teniendo además, motivos personales detrás, como es la separación del matrimonio que compraba).

La jurisprudencia de la entrega de vivienda es muy rica en detalles sobre los pormenores del contrato, como la STS 74I/20I4, de I9 de diciembre, establece que el mero retraso no siempre produce la frustración del fin del contrato, y por tanto no se puede equiparar al incumplimiento de la entidad. En otra sentencia del TS, de I 8 de mayo de 2016 (STS 322/20I6), indica que es doctrina jurisprudencial que «solo si las partes quisieron dar al plazo de entrega un carácter esencial con pactos resolutorios explícitos, el retraso del vendedor en la entrega ampara la resolución» $y$ «hay casos en que la jurisprudencia no da lugar a la resolución cuando se acredita que el plazo no era esencial y no frustra las expectativas contractuales de la parte compradora o cuando ésta, a su vez, incurrió en constantes incumplimientos o la demora fue insignificante y alegada cuando la vivienda ya estaba terminada», por lo que la cuestión del incumplimiento del plazo de entrega es una cuestión controvertida, que se complementa con la doctrina sobre el incumplimiento.

Es importante reseñar, como se dijo con la conformidad, que el incumplimiento ha de ser relevante, grave y esencial (vid. 7.I), de tal forma que el retraso en la entrega se entiende, ha de ser prolongado, y sin atender a los requerimientos que el consumidor hubiera hecho en plazo.

Ante las reclamaciones, también resulta normal que se incluyan cláusulas en el contrato por las cuales el comprador renuncia a acciones judiciales por el retraso en la entrega (lo cual contravendría el art. 86. TRLGDCU), o bien la previsión de que la fecha de entrega quedaría automáticamente anulada por el simple hecho de que los compradores solicitaran reformas en la vivienda (lo que supondría dejar a arbitrio del vendedor el cumplimiento del contrato, sancionado por el art. 85 TRLGDCU). 


\section{Conclusiones}

Del estudio realizado acerca de las cláusulas abusivas que pueden encontrarse en las diferentes fases de la compraventa inmobiliaria, se pueden extraer las siguientes conclusiones:

I.- Un complejo marco normativo que dificulta la determinación de la normativa a aplicar: La dispersión de la regulación en, al menos, tres cuerpos normativos (sin contar con las normas autonómicas que podrían dificultar aún más el estudio aunque, en el caso de La Rioja, no dificultan por ser meras reproducciones de normativa estatal) hace complicado establecer determinados puntos de la contratación inmobiliaria, especialmente en cuanto a los deberes legales de información.

2.- Se produce inseguridad jurídica en las obligaciones legales de información por su redacción ambigua y la falta de diligencia de las partes a la hora de contratar: De un lado, la profusión de normas que nos encontramos regulando los derechos-deberes de información han provocado, como se ha visto, que haya problemas de determinación de ley aplicable. Además de todo ello, la obligación mediante ley de que las partes han de ser informadas deja de lado que existan obligación de informar derivadas la buena fe, que ha de conformar toda relación contractual ${ }^{5 \circ}$.

3.- Clara desigualdad de condiciones empresario-consumidor ante la presencia de arras o cantidades anticipadas: La necesaria regulación establecida en relación a las cantidades anticipadas, y la extensa jurisprudencia en cuanto al desequilibrio producido ante cláusulas que regulan las arras, indican que éste es uno de los puntos con más problemática para los consumidores, con desmedido intento de lucro de las promotoras o constructoras. La aplicación del Derecho de consumidores, con la consideración del desequilibrio de obligaciones y derechos, salva al consumidor de una situación abusiva especialmente relevante (por las cantidades) en la compraventa inmobiliaria.

4.- Profusa relación de cláusulas declaradas abusivas en textos legales y jurisprudenciales: En este caso, la protección dada por la normativa y la jurisprudencia ante cláusulas insertas en los contratos resulta clara, y cubre jurisprudencialmente una casuística muy amplia, que permite conocer al consumidor (generalmente también por plataformas de consumidores), qué debe o no permitir en su contrato de compraventa inmobiliaria.

5.- Especial relevancia de la protección del consumidor en cuanto a conformidad, superficie y fecha de entrega: Sin duda, el momento de la contratación que suscita más reclamaciones es, ante un incumplimiento del vendedor, problemas con la conformidad de la vivienda recibida, problemas en cuanto a la superficie y retraso en la entrega. Se declaran abusivas las cláusulas que impongan al consumidor la conformidad con la vivienda sin que haya podido inspeccionarla previamente; del mismo modo que las cláusulas que no determinen de forma precisa la fecha de entrega, dispongan prórrogas automáticas o

\footnotetext{
${ }^{50}$ Alonso PÉrez, M.T., op. cit. pág. 295.
} 
limiten la responsabilidad. Todo ello en aras de evitar dejar al arbitrio del vendedor dichos aspectos tan relevantes, que suponen un desequilibrio importante entre las partes.

6.- Propuesta: Tras el estudio de la regulación establecida en materia de protección del consumidor en contratos de compraventa, creo preciso una armonización de las normas, dispersas entre el TRLGDCU, el RD 515/1989 (con una protección ya antigua que, si bien en su momento era innovadora, se ha quedado obsoleta con la protección del texto refundido), la LOE y otras, para asegurar una protección integral del consumidor en todo el proceso contractual.

\section{Bibliografía}

Álvarez LatA, N., «Cláusulas de repercusión de IVA, Plusvalía y otros costes del contrato» en Tratado de la Compraventa. Homenaje al profesor Rodrigo Bercovitz, Aranzadi, Pamplona, 2013, págs. 987-997 (Tomo II).

AlOnso PÉREZ, M.T., Las obligaciones legales de información precontractual en la compraventa de vivienda. A través del laberinto normativo, estatal $y$ autonómico en materia de vivienda $y$ de consumo, Aranzadi, Pamplona, 20 Io.

Busto LAGo, J.M., «¿Cabe aplicar «rebús sic stantibus» en un contrato de compraventa como contrato de tracto único?» en Tratado de la Compraventa. Homenaje al profesor Rodrigo Bercovitz, Aranzadi, Pamplona, 2013, págs. I723-I733 (Tomo II).

CABeZuelo Arenas, A.L., «Arras confirmatorias y penitenciales: reglas interpretativas» en Tratado de la Compraventa. Homenaje al profesor Rodrigo Bercovitz, Aranzadi, Pamplona, 2013, págs. 925934 (Tomo II).

CÁmara Lapuente, S., «Artículo 64 TR-LGDCU» en CÁmara Lapuente, S. (Director), Comentarios a las Normas de Protección de los Consumidores, Colex, Madrid, 20II, págs. 570- 578.

CASADO CASADO, B., «Percepción de cantidades a cuenta en la compra de viviendas. Resolución contractual y efectividad de la garantía. Jurisprudencia reciente y reforma tras la ley 20/2015, de i4 de julio», Revista para el Análisis del Derecho (INDRET) N ${ }_{4}^{\circ}$, Barcelona, 2016.

DíAz MARTíneZ, A., «Cláusulas abusivas en la compraventa de vivienda», en CARrasCo Perera, A. (Director), Tratado de la Compraventa. Homenaje al profesor Rodrigo Bercovitz, Aranzadi, Pamplona, 2013, págs. I077-I090 (Tomo II).

Dízz-PiCAzo, L.; Gullón, A.; Sistema de Derecho Civil. El contrato en general. La relación obligatoria; Tecnos, Madrid, II $^{a}$ edición, 2016.

DiéGuez Oliva, R., «Las cláusulas de cesión del denominado precontrato inmobiliario» en CaÑIZARes Laso, A., Cláusulas abusivas en la Contratación Inmobiliaria, Tecnos, Madrid, 2006, págs. 78-104.

DOMÍnguez ROMERo, J., La Recuperación de cantidades anticipadas por el adquirente de vivienda en construcción, Tirant lo Blanch, Valencia, 20II.

Instituto Nacional de Estadística, Censo de Población y Vivienda, Nota de prensa i2 de diciembre de 2013.

LUQUE JIMÉNEZ, M. C., «La cláusula reguladora del plazo de entrega de la vivienda» en CAÑIZARES LASO, A., Cláusulas abusivas en la Contratación Inmobiliaria, Tecnos, Madrid, 2006, págs. I46I60.

MondéfAR PeÑA, M.I., «La protección del consumidor en la Compraventa de Vivienda», en Humero MARTín, A.E. (Coord.), Tratado técnico-jurídico de la Edificación y del Urbanismo, Aranzadi, España, 2009, págs. 957-1064 (Tomo III).

Real ACAdemia Española, Diccionario de la Lengua Española, Espasa, Vigésima segunda Edición, $200 I$. 
SÁNCHEZ HeRnÁNDEZ, C., «El precontrato inmobiliario», en CAÑIZARES LASO, A., Cláusulas abusivas en la Contratación Inmobiliaria, Tecnos, Madrid, 2006, págs. 7I-77.

Sillero CrovetTo, B., «El Derecho a la información y la protección del consumidor en la compraventa de vivienda», en CAÑIZARES LASO, A., Cláusulas abusivas en la Contratación Inmobiliaria, Tecnos, Madrid, 2006, págs. 2I-5I.

TORRES LANA, J.A., «Deberes precontractuales de información en las compraventas de inmuebles al consumo» en CARrasco PererA, A. (Director), Tratado de la Compraventa. Homenaje al profesor Rodrigo Bercovitz, Aranzadi, Pamplona, 20I3, págs. IOII-IO20(Tomo II).

URREA SALAZAR, M.J. «El contrato de promesa de compra y las arras en la compraventa de bienes inmuebles», Inmueble: Revista del Sector inmobiliario, $\mathrm{n}^{\circ}$ I56, 20I5, págs. 32-37 (aunque la referencia en Dialnet es distinta).

\section{Tabla de jurisprudencia}

\begin{tabular}{|c|c|c|}
\hline No RESOLUCIÓN Y FECHA & RoJ & PONENTE \\
\hline \multicolumn{3}{|c|}{ AUDIENCIA PROVINCIAL } \\
\hline $\begin{array}{lllll}\text { SAP MAD } & 462 / 2007, & \text { de } & \text { I8 } & \text { de } \\
\text { septiembre }\end{array}$ & $\mathrm{I} 32 \mathrm{I} 3 / 2007$ & Guillermo Ripoll Olazabal \\
\hline SAP BAR $667 / 2012$, de i2 de diciembre & $13895 / 2012$ & Fernando Utrillas Carbonell \\
\hline SAP LO I23/20I2, 3 de abril & $243 / 2012$ & Alfonso Santisteban Ruiz \\
\hline SAP LO $27 / 2013$, de 4 de marzo & $152 / 2013$ & Alfonso Santisteban Ruiz \\
\hline SAP COR IO7/20I5, de 30 de marzo & $1045 / 2015$ & Carlos Fuentes Candelas \\
\hline
\end{tabular}

TRIBUNAL SUPREMO

\begin{tabular}{|c|c|c|}
\hline STS 6I/99, de 2 de febrero & $586 / 1999$ & Xavier O’Callaghan Muñoz \\
\hline STS 983/2000, de 24 de octubre & $7662 / 2000$ & Xavier O’Callaghan Muñoz \\
\hline STS $277 / 2002$, de 20 de marzo & $2001 / 2002$ & José Almagro Nosete \\
\hline STS 50I/2008, de 3 de junio & $3275 / 2008$ & Xavier O'Callaghan Muñoz \\
\hline STS I5I/20II, de I6 de marzo & $2494 / 2011$ & Juan Antonio Xiol Ríos \\
\hline STS 38I/20II, de 30 de mayo & $3402 / 2011$ & Jose Antonio Seijas Quintana \\
\hline STS $820 / 2013$, de I7 de enero & $\mathrm{IOI} 3 / 2013$ & Francisco Marín Castán \\
\hline STS I88/20I3, de 2I de marzo & $1836 / 2013$ & Antonio Salas Carceller \\
\hline 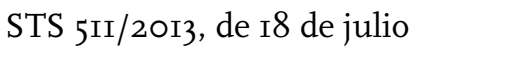 & $4245 / 2013$ & Rafael Saraza Jimena \\
\hline $\operatorname{STS}_{518 / 2013}$, de 23 de julio & $4086 / 2013$ & Francisco J. Arroyo Fiestas \\
\hline STS 2I3/20I4, de 2I de abril & $2389 / 2014$ & Jose Antonio Seijas Quintana \\
\hline STS 2I $8 / 2014$, de 7 de mayo & $239 \mathrm{I} / 20 \mathrm{I} 4$ & Francisco J. Arroyo Fiestas \\
\hline STS 74I/20I4, de I9 de diciembre & $5347 / 2014$ & Antonio Salas Carceller \\
\hline
\end{tabular}




\begin{tabular}{l|l|l} 
STS 744/20I4, de 22 de diciembre & $5379 / 2014$ & Xavier O’Callaghan Muñoz \\
\hline STS I60/20I5, de Io de septiembre & $4003 / 2015$ & Sebastian Sastre Papiol \\
\hline STS 476/20I5, de Io de septiembre & $3723 / 2015$ & Francisco Marín Castán \\
\hline STS 50I/20I5, de I5 de septiembre & $3876 / 2015$ & Francisco J. Arroyo Fiestas \\
\hline STS 322/2016, de I8 de mayo & $2136 / 2016$ & Xavier O’Callaghan Muñoz \\
\hline STS 56I/20I6, de 23 de septiembre & $4179 / 2016$ & Ángel Fernando Pantaleón Prieto \\
\hline STS 626/20I6, de 24 de octubre & $4646 / 2016$ & Ignacio sancho Gargallo \\
\hline STS 739/20I6, de 2I de diciembre & $2391 / 2016$ & Francisco J. Arroyo Fiestas \\
\hline STS 65/20I7, de 23 de febrero & $329 / 2017$ & Francisco Marín Castán \\
\hline STS 447/20I7, de I3 de julio & $2848 / 2017$ & Ma de los Ángeles Parra Lucán \\
\hline STS 502/20I7, de I4 de septiembre & $3280 / 2017$ & Francisco Marín Castán \\
\hline STS 547/20I7, de Io de octubre & $3611 / 2017$ & Francisco Marín Castán \\
\hline
\end{tabular}

